\title{
Louviers - Quartier des Oiseaux, rue des Oiseaux
}

$n^{\circ} 17-2293$ et $17-2379$

Maud Le Saint Allain

\section{(2) OpenEdition}

Journals

Édition électronique

URL : http://journals.openedition.org/adlfi/16622

ISSN : 2114-0502

Éditeur

Ministère de la culture

Référence électronique

Maud Le Saint Allain, «Louviers - Quartier des Oiseaux, rue des Oiseaux », ADLFI. Archéologie de la France - Informations [En ligne], Haute-Normandie, mis en ligne le 18 février 2016, consulté le 02 mai 2019. URL : http://journals.openedition.org/adlfi/16622

Ce document a été généré automatiquement le 2 mai 2019.

(c) Ministère de la Culture et de la Communication, CNRS 


\title{
Louviers - Quartier des Oiseaux, rue des Oiseaux
}

$n^{\circ} 17-2293$ et $17-2379$

\author{
Maud Le Saint Allain
}

Lien Atlas (MCC) :

http://atlas.patrimoines.culture.fr/atlas/trunk/index.php?

ap_theme=DOM_2.01.02\&ap_bbox=1.106;49.192;1.205;49.250

1 Un projet de lotissement sur les secteurs de la rue des Oiseaux et du quartier des Oiseaux a conduit au diagnostic de deux parcelles, sur une surface totale de 1,1 ha. Au quartier des Oiseaux, en raison de la présence de bâtis en élévation et d'une voirie encore en usage, les sondages ont été limités aux parcelles accessibles et seuls $2500 \mathrm{~m}^{2}$, sur les $7000 \mathrm{~m}^{2}$ de la prescription, ont pu être explorés. Rue des Oiseaux, le diagnostic a concerné les $4100 \mathrm{~m}^{2}$ d'un jardin public situé autour d'un terrain multisport.

2 Les résultats de cette opération révèlent la présence de niveaux de remblais attestant le remaniement de ces parcelles au $\mathrm{XIX}^{\mathrm{e}} \mathrm{s}$. Les vestiges des fondations d'une maison de maître étaient connus par la cartographie ancienne ; les sondages effectués ont permis de restituer une maçonnerie alternant moellons calcaire et briques industrielles. De nombreux artéfacts, notamment céramiques, témoignent d'une fondation ou du moins d'une fréquentation de ce bâtiment au $\mathrm{xVII}^{\mathrm{e}} \mathrm{s}$. Un second bâtiment situé du côté de la rue des Oiseaux a également été découvert à $30 \mathrm{~m}$ de distance. De plan quadrangulaire, il se rattache manifestement à cette occupation et pourrait correspondre à un ancien pavillon de chasse. Les autres découvertes sont également contemporaines : elles consistent en un caveau/cellier et deux tronçons de murs très arasés. Ces résultats concordent avec ceux du diagnostic limitrophe réalisé d'un même tenant au quartier des Oiseaux ayant livré des maçonneries de même nature ainsi qu'un puits. Ils nous renseignent sur l'existence au XIX ${ }^{e} s$. d'un grand domaine, certainement lié au développement des filatures qui incita à l'extension de la trame urbaine. Pour les périodes plus anciennes, seule une fosse, ayant livré les tessons d'une céramique commune claire dorée au mica, illustre la période 
antique. Quelques silex taillés, retrouvés en position secondaire dans les niveaux perturbés, témoignent d'une fréquentation du lieu à la Préhistoire. Ceci semble confirmer les observations plus générales effectuées sur le fond de vallée, à l'occasion de différentes opérations, où les périodes anté-médiévales sont peu représentées.

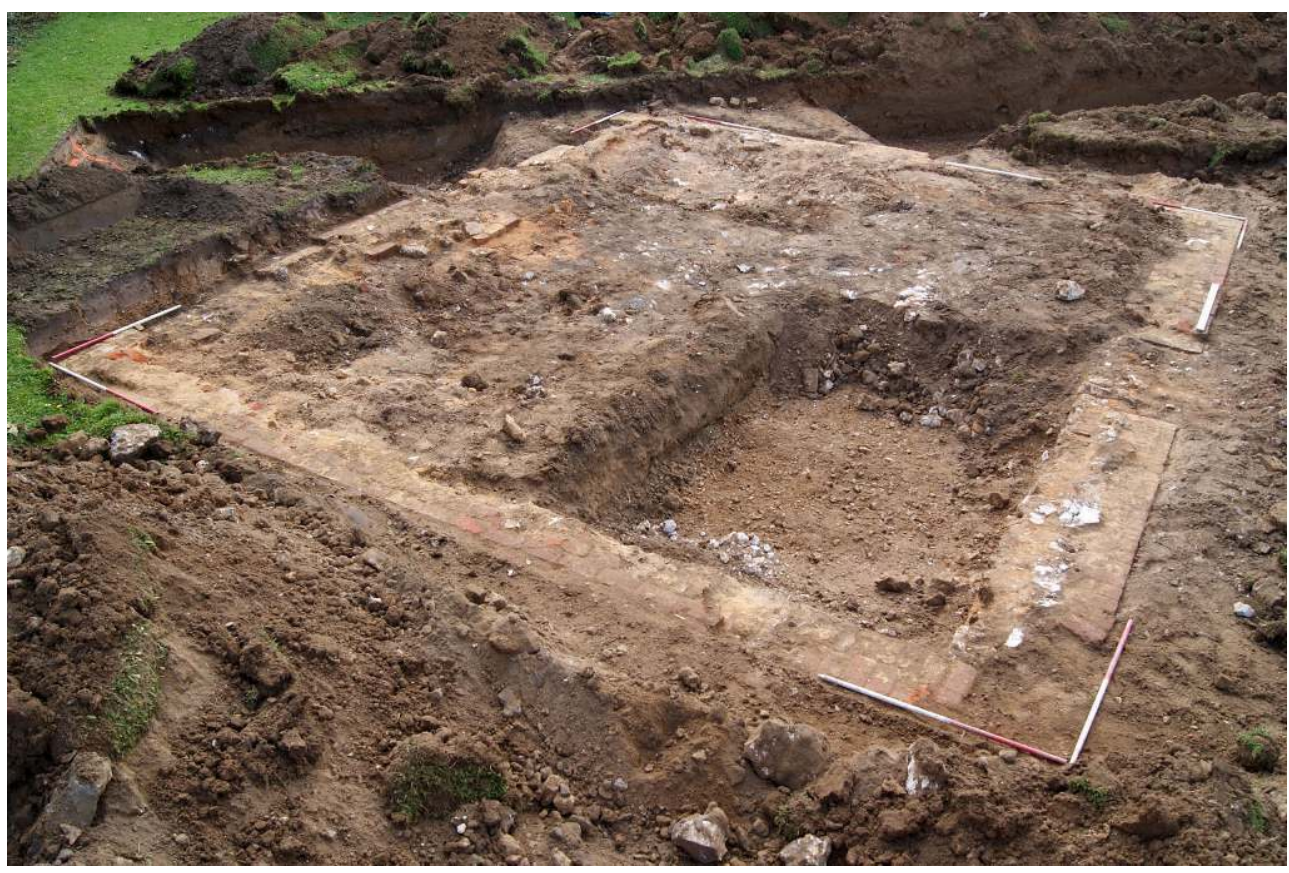

Fig. 1

Vue des fondations d'un ancien pavillon de chasse

G. Deshayes

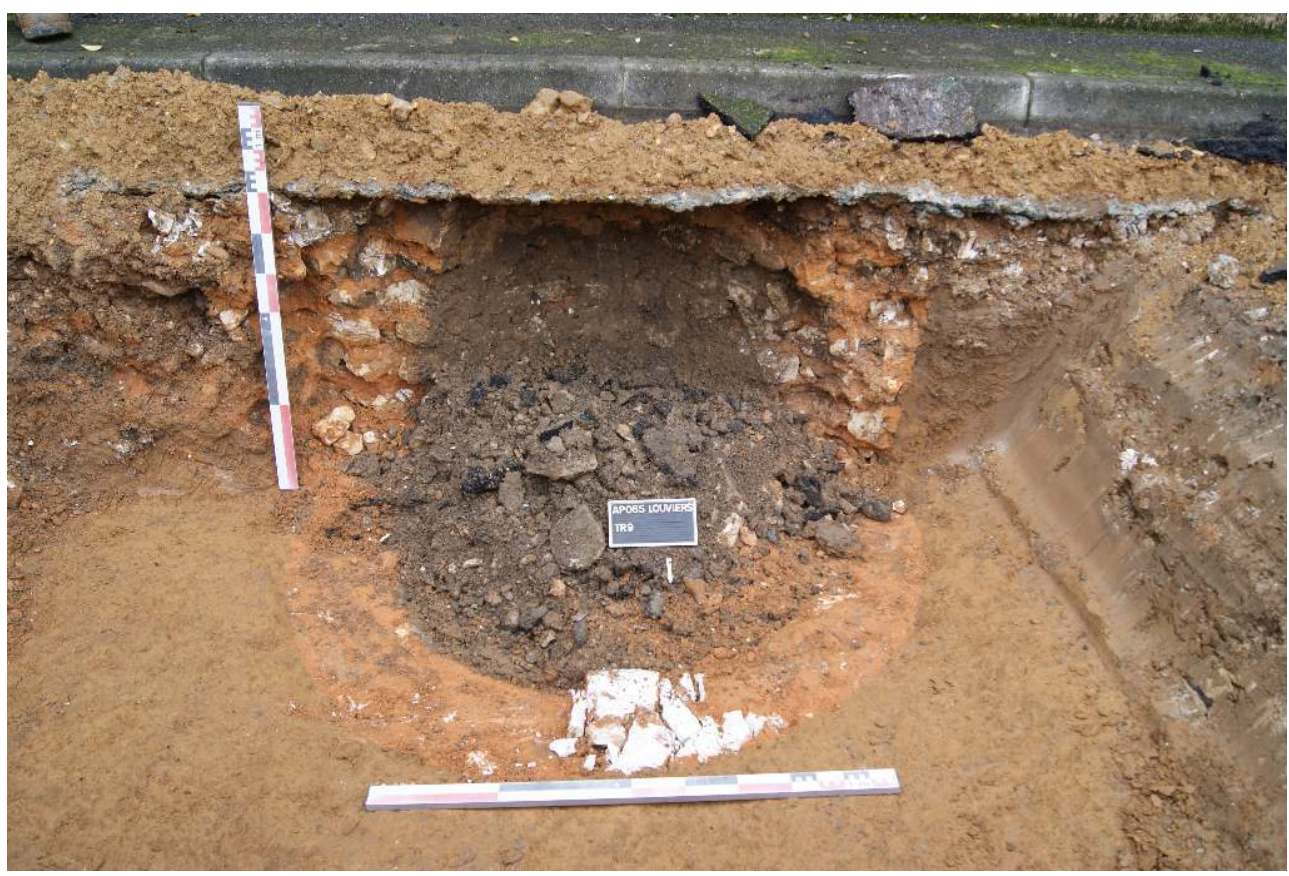

Fig. 2

Vue du puits du XIXe s. au pied des immeubles Seine et Oise 
INDEX

Index chronologique : Néolithique, ép. contemporaine, Temps Modernes

Index géographique : Normandie, Eure (27), Louviers

operation Opération préventive de diagnostic (OPD)

Mots-clés : céramique, bâtiment, pavillon de chasse, cellier, puits

\section{AUTEURS}

\section{MAUD LE SAINT ALLAIN}

Mission Archéologique de l'Eure 